Jakub Kruszewski ${ }^{1,2}$, Daniel Worobiej ${ }^{1,2}$, Weronika Kolasińska ${ }^{1,2}$, Rafał Andrzej Sokołowski ${ }^{2}$, Michał Rząd ${ }^{2,3}$

${ }^{1}$ Faculty of Medicine, Medical Univeristy of Warsaw, Warsaw, Poland

${ }^{2}$ Department of Internal Diseases, Pneumonology, Allergology and Clinical Immunology, Military Health Institute, Warsaw, Poland

${ }^{3}$ Department of Social Medicine and Public Health, Medical University of Warsaw, Warsaw, Poland

\title{
Potential benefits and hazards associated with the use of e-cigarettes - a guide for practitioners and current status in Poland
}

\begin{abstract}
The use of electronic cigarettes has dynamically increased over the last few years. Meanwhile, the knowledge regarding their safety has been rapidly changing, which could be a challenge for a medical practitioner. The purpose of this review is to summarize the latest reports and to verify statements on e-cigarettes' influence on health, including in the context of the ongoing SARS-CoV-2 pandemic. Awareness of the benefits of e-cigarettes can provide vital support for doctors caring for patients who smoke traditional cigarettes. Nevertheless, attention should be paid to the dangers of the medically unjustified use of electronic cigarettes. Despite the idea of releasing e-cigarettes into the market as a harmless alternative to traditional cigarettes, this product also has a negative impact on health. Replacing traditional cigarettes with e-cigarettes provides well-documented benefits to patients with certain indications such as hypertension and asthma, as well as to smokers who intend to minimize the negative effects of passive smoking on their environment. Moreover, it could be valuable for patients who are willing to permanently overcome a nicotine addiction, especially when previous attempts to quit smoking with nicotine replacement therapy (NRT) monotherapy were unsuccessful. Electronic cigarettes are a rapidly developing technology and an innovative form of a well-known addiction, so it is essential for practitioners to stay informed.
\end{abstract}

Key words: electronic cigarettes, smoking, nicotine addiction, SARS-CoV-2

Adv Respir Med. 2021; 89: 392-402

\section{Introduction}

The popularity of e-cigarettes worldwide has considerably increased over the last few years. It is claimed that they are consistently used by $1,4 \%$ of the Polish population aged 15 and older, and 4\% declare having used them at least once [1]. From 2014 to 2017 , a $20 \%$ increase in their use had been noted in the European Union. Currently, it involves almost $2 \%$ of Europeans [2]. Numerous myths have existed in the public sphere and the confidence in their authenticity is the reason why the popularity of the phenomenon called vaping is growing. In Poland, aside from being a fashionable trend, the primary reasons for using e-cigarettes include them being a healthier alternative to smoking, the belief in their efficacy in overcoming nicotine addiction, and saving money [3]. Foreign studies confirm that the most common excuse for the initiation of e-cigarette usage is a conviction about their beneficial effects on smoking cessation and on the environment [4]. The increase in e-cigarette use is particularly high among young people [5].

An electronic cigarette is a small, battery-powered device filled with liquid containing nicotine. It gives an impression of traditional cigarette smoking [6]. The Polish legal definition describes an e-cigarette as a "product which is used for the consumption of vapour containing nicotine by using a mouthpiece [...]; e-cigarettes may be of 
single-use or can be refillable [...]" [7]. Currently, an e-cigarette resembles a thick pen made of two parts: a source of power, hence a battery, and a vaporizer with a container filled with fluid, which contains nicotine in various concentrations and flavours, as well as typically glycerine and propylene glycol. Nicotine consumption is based on inhaling steam produced as a consequence of boiling this liquid. Such a process does not produce smoke, which is associated with traditional cigarettes.

In Poland, the addiction to e-cigarettes has expanded specifically among the younger generation $-60 \%$ of middle school students admit using both traditional and electronic cigarettes, another $10 \%$ declare the use of just e-cigarettes, and 11\% of teenagers who have not tried traditional ones tried an electronic cigarette during the last thirty days (an increase of over $1 / 3$ as compared to the time period between 2014-2017). Subsequently, the percentage of people who regularly vape has risen three times over - up to $6 \%$. Generally, the proportion of people who have used e-cigarettes exclusively during the last thirty days has grown fivefold from $2 \%$ in $2010-2011$ to $11 \%$ in 2015 2016. As high as $24 \%$ of interviewed individuals confirm the consumption of both electronic and traditional cigarettes over the last thirty days. It represents a sixfold increase from $4 \%$ in 2010 2011 to $24 \%$ in 2015-2016 ( $<<0.05$ ) [5].

Even though the percentage of smokers has slightly decreased in our country (from $24 \%$ in 2017 to $21 \%$ in 2019 with a statistically unvarying difference between men and women), the number of people reaching for e-cigarettes has grown, especially among young people living in cities with more than 100,000 inhabitants [1, 3]. Taking into account the expansion of e-cigarette use in Poland, the aim of this review is to elaborately summarize the current state of knowledge concerning their potential benefits and hazards.

\section{Influence on the respiratory system}

Traditional cigarettes have been proven to have significant adverse effects on the respiratory system and are the main cause of lung cancer and chronic obstructive pulmonary disease (COPD) [8]. This toxic influence is derived from the occurrence of many hazardous substances in tobacco smoke. Studies showed that they initiate the inflammatory process resulting in the development and progress of COPD and lung cancer $[9,10]$. In recent years, the morbidity and mortality from COPD has notably increased [11]. According to the estimated data, 2 million people in Poland suffer from this disease and 15 thousand die from its complications every year. It is well-known that adults who smoke traditional cigarettes have a $61 \%$ greater risk of developing asthma, and a 1.71 times greater risk of exacerbations of asthma in comparison to non-smokers $(p<0.05)$ [12]. Furthermore, it is confirmed that children who are subject to passive smoking have a $20 \%$ greater risk of developing asthma. The need to utilize corticosteroids for asthma exacerbations increases by $1.71(\mathrm{p}=0.004)[13,14]$. Additionally, the fetal exposure to tobacco smoke is associated with lung underdevelopment and other minor dysfunctions which lead to obstructed air flow later in life [15].

The presence of many toxic substances in tobacco smoke has not been confirmed in e-cigarette vapour. However, flavour extracts present in e-cigarettes may expose their users to health risks [16]. Moreover, according to research where the influence of 5-minute usage of an e-cigarette on lung function was tested among healthy adults, it was found that even short-term vaping causes immediate serious adverse effects similar to traditional cigarette smoking [17].

Multiple sweet aromas were tested with the aim of searching for toxic chemical substances. The findings have shown that most of the samples contained diacetyl, the presence of which was associated with the occurrence of bronchiolitis obliterans, also called "popcorn lung" $[16,18]$. Importantly, the in vivo study has demonstrated the inefficiency of cellular protease as a consequence of aerosol exposure, which suggests the potential role that e-cigarettes may have in the pathogenesis of emphysema in COPD [19]. Additionally, there is a $39 \%$ greater risk of developing asthma among current e-cigarette users as compared to people who have never used them. At the same time, the increased intensity of usage was observed to be associated with an increased probability of asthma development [20]. On the other hand, the substitution of traditional cigarettes for electronic cigarettes among people already diagnosed with asthma was observed to be associated with long-term benefits such as alleviation of symptoms and better asthma control with a reduction in the number of exacerbations [21]. Nonetheless, one of the e-liquid ingredients, propylene glycol, may worsen both asthma and COPD despite being relatively non-toxic [22].

In July of 2019, the Wisconsin Department of Health Services and the Illinois Department of Public Health received many notifications about lung injuries associated with e-cigarette usage 
(EVALI, e-cigarette, or vaping, product use-associated lung injury), which started coordinated research projects in order to establish the exact cause of this pathology. On the $6^{\text {th }}$ of September 2019, there were 98 patients who matched the definition of probable or confirmed cases of EVALI. The average age was 21 . The chief reported complaints involving the respiratory system (especially shortness of breath, cough, and chest pain) as well as the digestive system (particularly nausea, vomiting, diarrhea, and abdominal pain). Among 81 extensively interviewed patients, 73\% of them admitted using nicotine products and $89 \%$ of the products contained tetrahydrocannabinol, the basic psychoactive substance in cannabis [23]. According to another study from 2019, e-cigarettes were associated with a wide variety of lung diseases, primarily acute eosinophilic pneumonia, diffuse alveolar damage, and lipoid pneumonia. Presumably, the contributory factor in these pathological entities is tocopheryl acetate, also known as vitamin $\mathrm{E}$ acetate, an additive in e-liquids with tetrahydrocannabinol [24]. The analysis of the bronchoalveolar lavage led to the detection of vitamin $\mathrm{E}$ acetate in the epithelial lining fluid (ELF) among 48 of 51 patients with EVALI and, concurrently, the absence of this ester was confirmed in the healthy controls [25]. By the $18^{\text {th }}$ of February 2020, the CDC had 2,807 reported cases of hospitalized or dead EVALI patients [26]. It should be emphasized that, in European Union countries where THC is forbidden, EVALI was not observed [27].

\section{Influence on the circulatory system}

The detrimental effect of traditional cigarette smoking on the cardiovascular system has been thoroughly acknowledged and described. Its association with coronary artery disease, myocardial infarction, arteriosclerosis, aortic aneurysm formation, and peripheral arterial disease has been proven. The harmful outcome of passive smoking was also confirmed [28]. Furthermore, studies on monozygotic twins where only one of them was a traditional cigarette smoker revealed that a smoking sibling had the median plasma renin activity $99 \%$ greater at rest and $84 \%$ greater during a submaximal exercise as compared to the other twin $(\mathrm{p}<0.01)$. Additionally, during exercise, the smokers had the median level of aldosterone generally $40 \%$ greater than their nonsmoking siblings $(\mathrm{p}<0.05)$. This phenomenon partly explains the tendency for vasoconstriction to occur in traditional smokers [29].
Considering the above, adverse effects of traditional cigarettes may be divided into those resulting from nicotine toxicity and those associated with other chemical substances and physical factors. Nicotine acts as sympathomimetic, thus it increases myocardial oxygen demand [30]. Moreover, it was shown that in rats with primary hypertension, it augments a risk of developing hypertrophic cardiomyopathy [31]. Another toxic substance present in tobacco smoke is carbon monoxide (CO), which binds with hemoglobin thus reducing the oxygen-binding capacity of blood. As a consequence, it leads to hypoxemia, overproduction of erythrocytes, and hypercoagulability [32]. The correlation between smoking and raised inflammatory markers was also proven [33]. The chemical composition of classic cigarettes was examined providing information about the presence of heavy metals in tobacco smoke - particularly manganese, nickel, and chrome [34]. These metals catalyze protein oxidation in epithelial cells, resulting in their malfunction [35]. In addition, the cobalt concentration in the aorta correlates with the number of smoked pack-years, which increase the risk of aortic aneurysm formation [36]. As a consequence of the above factors, the risk of developing cardiovascular disease increases.

Hazardous substances discovered in e-cigarette vapour include nicotine and heavy metals. However, it seems that the concentration of heavy metals in aerosols does not appear to be at toxic levels and is certainly lower than the concentration in traditional cigarette smoke [37]. In turn, the amount of nicotine and its resulting toxicity varies due to different liquids used in different types of these devices ranging from nicotine-free cartridges to ones with a nicotine content higher than in classic cigarettes [38].

It was proven that e-cigarettes elevate both the systolic and diastolic blood pressure and increase the heart rate, but to a much lesser degree than traditional smoking. Furthermore, e-cigarettes have no influence on the amount of exhaled carbon monoxide, which is in marked contrast to classic cigarette smoke (eight times greater than the baseline) [39]. Among smokers treated for hypertension, e-cigarettes facilitated a reduction in systolic and diastolic blood pressure. This effect was long-lasting and was seen early in the course of treatment when smokers of classic cigarettes were beginning to use e-cigarettes, which at the same time limited the use of the classic ones [40]. A prospective study based on healthy young individuals aged $29.7( \pm 6.1)$ 
did not show a negative impact of e-cigarettes on the circulatory system (respiratory rate [RR], systolic and diastolic blood pressure [SBP and DBP]) after 3.5 years of vaping. Presumably, we should wait longer to observe the adverse effects of aerosol exposure. Currently, long-term studies of this kind are not available [41].

\section{Influence on carcinogenesis}

The inhaled smoke from classic cigarettes is recognized as the main cause of neoplasia [28]. Multiple substances present within this smoke qualify as carcinogenic substances according to the International Agency for Research on Cancer [42].

Considering the influence of e-cigarettes on the development of oncologic conditions, there are only a few studies which have been conducted in the recent past. Currently, there is no clear evidence-based affirmation of the carcinogenic role of vaporizers. The majority of conclusions are based on studies involving animal and cell cultures [43].

In its 2018 report, the American National Academy of Sciences, Engineering and Medicine (NASEM) informed about the influence of e-cigarettes on public health, including the risk of carcinogenesis. The report states that the only correct conclusion which can be made from the up-to-date research is the confirmation of the presence of mutagens in e-cigarettes' aerosol. Indeed, these substances are proven, both in vitro and in vivo, to damage DNA. In high concentrations, they have also been proven to damage human DNA, yet they cannot be explicitly connected with the possibility of carcinogenesis among active e-cigarette users. Further research is required to clarify if the concentration of these mutagens in the inhaled aerosol is sufficient enough to initiate mutagenesis. However, there is limited existing evidence showing increased carcinogenesis in animal models secondary to long-term exposure to e-cigarette vapour [44].

Since the publication of the NASEM report, new studies have suggested the possibility of the causal association between e-cigarettes and the development of cancer. For instance, mice which were exposed to this aerosol for 54 weeks had a significant tendency to develop lung adenocarcinoma $(22,5 \%$ out of 40 animals involved in this experiment) as well as urothelial hyperplasia of the bladder $(57,5 \%$ out of 40$)$. In the control group, there was only one mouse out of 40 which developed lung cancer [45]. In another research article, experimental mice were implanted with breast cancer cells. The prevalence of tumor progression was horrific. $100 \%$ of the animals which had been previously exposed to e-cigarette aerosol developed cancer, compared to $33 \%$ in the control group which had only been breathing room air. Moreover, this progression was evidently faster in the exposure group than in the control group. Lung metastases were also significantly more frequent among rodents from the exposure group. The same research clearly confirmed the increase of the capability of pathologic cells to escape apoptosis after exposure to e-cigarette vapor [46]. Based on these observations, it was assumed that vaping was associated with tumor progression as well as with a limitation of the immune response, which enabled destruction of cancer cells shortly after their implantation. Another study validated an increase in the degree of DNA degradation and a decrease in its repair activity in mice lungs, hearts, and bladders, as well as in cell cultures obtained from human lung and bladder cells ( $p<0.05$ ) [47].

There are only a few studies on the subject of the health hazards of passive e-cigarette smoking. Even though there are significantly lower concentrations of toxic substances in the aerosol than in tobacco smoke, they can potentially lead to serious consequences, especially when vaping takes place in a limited, enclosed space, and when there is a high concentration of vapour. Passive smoking may possibly result in irritation of the airways from inhaling glycerol and propylene glycol vapour. The effects of nicotine aspiration (activation of the sympathetic nervous system, increased blood pressure, and tachycardia) as well as the potentially mutagenic activity of tobacco-specific nitrosamines should also be taken into consideration, although they are not currently included in most of the liquids [48]. It seems that the use of e-cigarettes in closed spaces does not endanger passive smokers by noxious concentrations of toxic substances. However, the influence of nicotine may be perceptible and potentially adverse [49]. No evidence has been found pointing to increased carcinogenic risk or the absence of such a risk in individuals exposed to passive electronic cigarette smoking. The only undeniable fact is that smokers are subject to a lower concentration of toxic substances while using electronic devices rather than traditional cigarettes [44].

\section{Influence on the oral cavity}

There are two main dental problems related to tobacco smoke exposure: tooth decay and 
influence of NRT on birth weight is still unclear. The findings are actually contradictory [64, 65].

Studies conducted on animal models appear to be more suggestive yet still insufficient. They showed normal birth weight of offspring of mothers who were exposed to e-cigarette vapour. However, their subsequent growth was stunted as opposed to individuals born in a control group [60]. Additionally, studies which were performed on rats reported that rodents previously exposed to vaping delivered low birth weight offspring in contrast to rats from the control group, and this difference was statistically significant. The same research also presented a distinct decrease of blood flow in the uterine artery (49.5\%) and in the umbilical artery (65.3\%) among the experimental group versus the comparison group $(\mathrm{p}<0.05)$ [66].

\section{Difference in the cost of smoking traditional cigarettes and vaping}

It is still a challenge to formulate a precise analysis about costs borne by people smoking classic cigarettes as opposed to e-cigarette users. It comes from the fact that there is a great diversity between prices of traditional cigarettes and a wide range of prices of electronic cigarettes. The comparative analysis from 2017, performed on the basis of estimated data collected from 45 countries comparing the prices of equal units of nicotine, showed that traditional cigarettes are generally cheaper than single-use e-cigarettes. In the USA, this difference was $\$ 6.82$ vs $\$ 7.99$. In Poland, the difference was $\$ 4.18$ vs $\$ 4.76$. On the other hand, the price of liquid refills used in multiple-use e-cigarettes may be lower than classic cigarette packs, although the initial purchase of multiple-use electronic cigarettes poses a definitive financial burden on people exchanging smoking for vaping. After proper review of prices of traditional cigarettes and electronic multiple-use devices, the authors of this analysis estimated the time needed to recover the initial expense of switching to e-cigarettes for each country. In Poland, this amounted to a total of 6 days [67]. Nevertheless, it should also be emphasized that on the $1^{\text {st }}$ of July 2020, a new tax was implemented on e-cigarettes in Poland which may result in a change in the calculations described above.

\section{Dual use of nicotine products}

The introduction of e-cigarettes is associated with a certain risk of simultaneous use with traditional cigarettes, which constitutes a phenomenon known as dual smoking (i.e. dual users). During three time periods (2010-2011, 2013-2014, and 2015-2016), with the aid of an anonymous questionnaire intended for upper-secondary students and technical school students in Poland $(\mathrm{n}=$ 5708), data was collected regarding current and previous tobacco smoking and e-cigarette use. $45 \%$ of the respondents confirmed a dual supply of nicotine in the past, and $17 \%$ of them admitted to dual use during the 30 days preceding the filling out of the questionnaire [5]. According to a Polish nationwide cross-sectional study from 2019, $28.6 \%$ of people declaring e-cigarette usage were also smoking traditional cigarettes on a daily basis [1]. It is a common phenomenon and every vape enthusiast is potentially subjected to a growing tendency towards additional exposure to tobacco smoke. Data from surveys gathered in the USA also confirmed this foregoing regularity $-31.8 \%$ of former users and $34.6 \%$ of current e-cigarette users (during the last 30 days) answered affirmatively to the question about any additional classic cigarette smoking [68]. Importantly, it was proven that teenagers using exclusively electronic cigarettes displayed a stronger tendency towards the new onset of traditional smoking during a 5 year follow-up in comparison to non-users of these devices [69]. However, it should be stressed that this statement is only correct with regards to e-cigarette users without a documented strong nicotine addiction. In fact, people with an advanced addiction to nicotine who have been consistently using e-cigarettes are less prone to simultaneous traditional cigarette smoking [70].

The addiction to classic cigarettes and e-cigarettes was analyzed in the research conducted in 2018 on a group of dual smokers using specially designed psychometric measures. On average, stronger addiction to traditional cigarettes was reported than to electronic ones. The differences in nicotine craving in both methods of delivery were documented, which suggests that dual users may actually differentiate the degree of addiction to each of these products [71]. Another study confirmed that e-cigarette users regarded vaping as causing less dependence to nicotine. Additionally, for people inhaling the aerosol, it was easier to restrain themselves from smoking in places where it was forbidden. The same group also reported a longer time from awakening to the first intake of nicotine in comparison to traditional smokers [72].

\section{Combating nicotine addiction}

A potential role of e-cigarettes in the process of overcoming smoking addiction is not suffi- 
ciently known. In January 2018, The US Surgeon General reported various conclusions of differing potential. The authors of this report confirm the presence of limited evidence for e-cigarette use in the process of overcoming the addiction to smoking. Statements which suggested a greater efficacy of e-cigarettes containing nicotine were actually believed to be of moderate strength. Documentation regarding the advantage of e-cigarette use in combating addiction over other methods approved by the FDA (i.e. NRT, varenicline, bupropion) was found to be insufficient [44]. Nevertheless, new and high-quality research conducted shortly after the publication of the above report allowed for new light to be shone on previously provided conclusions. A British study which compared the effectiveness of NRT and e-cigarettes based on a sizable sample of patients (about 700 people in two corresponding size groups which finished an annual program) showed that e-cigarette use had an eminently better result for the purpose of overcoming nicotine dependency. The percentage of the annual success rate in a group which used traditional replacement therapy was $9.9 \%$, whereas it was almost twice as high in a group using e-cigarettes $(18 \%)$ ( $p<0.001)$. Both types of therapy were assessed as less satisfying than smoking cigarettes by patients who took part in research studies. However, vaping was graded higher than NRT. E-cigarette users reported less irritability and fatigue, and a better ability to concentrate (relative to the initial stage) than patients receiving nicotine replacement therapy. Nausea was also less frequent in the vaping group. The NRT profile was more preferable in only two subgroups: those where there was a general degree of irritation of the oral cavity and throat (63.5\% vs $51.2 \%$ ), and in those where the irritation was severe $(5.9 \%$ vs $3.9 \%$ ) [73]. The helpful role of e-cigarettes was also noted in a study conducted on a group of over 1,100 smokers in which the efficacy of three therapies was compared. One of them was based on a monotherapy with the use of nicotine patches, whereas two others were combination therapies based on patches and e-cigarettes with nicotine-containing liquid or nicotine-free liquid. NRT without the addition of electronic cigarettes showed the lowest success rate. The group which received traditional replacement therapy had the highest percentage of patients who finished the participation in the program prematurely. NRT supplemented by e-cigarettes with nicotine was seen to provide the most effective method of quitting smoking, both during semi-annual and annual periods. Depending on the observation's time period, this method was from 3 to 7 percentage points more efficacious than the one with nicotine-free e-cigarettes. According to the authors, the optimal therapy was also 5 to 10 percentage points more successful than monotherapy with nicotine patches $(\mathrm{p}<0.05)$ [74].

Yet another study showed that the use of e-cigarettes, which are similar in appearance to classic cigarettes, may be more successful in combating nicotine cravings than the use of devices which have a different appearance (i.e. most e-cigarettes of the newest generation). Despite a small sample size $(n=63)$, this study may present a valuable clue to people trying to overcome the addiction [75].

\section{The association with COVID-19}

The SARS-CoV-2 pandemic requires careful and new reflection in the context of the safety profile of e-cigarettes. The research conducted in July 2020 revealed that both smoking tobacco and vaping may increase vulnerability to COVID-19. However, it should be emphasized that e-cigarettes, which do not contain nicotine, contribute to the development of these changes to a much lesser degree than classic cigarettes. In contrast to the exposure to e-liquid aerosol, smoking tobacco was also proven to increase ACE2 expression - a cell receptor with a high-affinity for SARS-CoV-2 [76].

Patients who have a positive history of smoking tobacco show a much higher risk of having a severe course of the coronavirus disease (COVID-19) (RR: 1.31), in-hospital mortality (RR: 1.26), subsequent progression of disease (RR: 2.18), and need for mechanical ventilation (RR: 1.20) [77].

According to an online study conducted in May 2020 among teenagers and young adults (n $=4351$ ) between the ages of 13 and 24 , the diagnosis of COVID-19 is five times more probable for exclusive e-cigarette users and seven times more probable for dual smokers [78]. Moreover, considering the potential acute toxicity of electronic cigarettes involving the lungs and cardiovascular system, the use of these products may expose patients infected with SARS-CoV-2 to a greater risk of developing a severe course of COVID-19 [79].

\section{Discussion}

The period of over ten years where e-cigarettes have been present on the market have not been able to unequivocally prove and/or assess long term effects of their use. The intensification 
of research associated with the increasing use of these devices provided strong information which should influence the perception of e-cigarette use by general practitioners. Based on the above review of literature, we would like to carefully investigate potential benefits as well as risks associated with e-cigarette use.

Vaping as a replacement for smoking classic cigarettes is beneficial to patients diagnosed with bronchial asthma. The exposure to aerosol rather than tobacco smoke contributes to a decrease in respiratory system symptom intensity and to an improvement in lung function. At the same time, it should be emphasized that e-cigarette use predisposes to the development of asthma, although the risk of its occurrence seems to be lower than that of traditional smokers. A possible decrease in the risk of developing COPD is the additional advantage - classic cigarettes are the major etiopathological factor here, whereas vaping was not unequivocally associated with it.

A particular benefit of exchanging traditional cigarettes for electronic ones is seen in patients suffering from hypertension. In this group, the positive change in blood pressure is statistically significant and permanent. However, it should be noted that any form of nicotine, a sympathomimetic, causes temporary elevation of the systolic blood pressure. It is particularly important in patients with poorly controlled hypertension. In this case, the use of liquids with low nicotine content might be preferable. Additionally, a significantly lower amount of toxic metals coupled with the lack of CO emission by electronic cigarettes decreases the cardiovascular risk.

In marked contrast to classic cigarette use, there were no documented cases of cancer development in humans due to e-cigarette use. However, animal-based research indicated possible carcinogenesis as a result of aerosol exposure. Therefore, a practitioner who treats patients with a positive history of using electronic cigarettes needs to remain oncologically alert. A convincing argument in favour of exchanging traditional cigarettes for vaporizers is their less harmful, if any, influence on "passive smokers" - aerosols do not contain confirmed carcinogens, whereas tobacco smoke is a rich source of them.

Currently, there is no sufficient evidence confirming the superiority of using e-cigarettes over traditional cigarettes in relation to oral cavity disease prevention. Serious afflictions caused by tobacco smoke, such as precancerous conditions or squamous cell carcinoma, were not convincingly associated with exposure to e-liquid aerosols. Pa- tients undergoing dental care may potentially benefit from an exchange of classic cigarettes for electronic devices. However, it should be noted that the sweet aromas contained in liquids cause more frequently observed occurrences of decay, hence they should be avoided.

E-cigarettes are confirmed to be an effective way of fighting nicotine addiction. They have a greater efficacy in comparison with a single NRT according to studies from recent years published in prestigious periodicals (Nature, The Lancet). In the process of combating the addiction, electronic cigarette use also decreases the intensity of unpleasant feelings associated with withdrawal from nicotine, which results in fewer treated patients who terminate the therapy prematurely. Moreover, social functioning is relatively easier for those individuals who use vaporizers during their combat with nicotine addiction because of their lower irritability and fatigue, unlike among smokers.

A significant hazard associated with e-cigarette use is the phenomenon of dual smoking. Not only can it cause the summation of negative effects of both of these stimulants, but also increases the addiction to nicotine and can render the potential future fight with the addiction to be more difficult. This problem is fairly common, hence every practitioner in contact with a vaping person should evaluate it on an ongoing basis. It is absolutely vital for dual smokers to gradually limit smoking traditional cigarettes. It allows for early substantial benefits to the circulatory system and additionally facilitates reduction of nicotine intake.

The substitution of classic cigarettes for e-cigarettes also provides for practical financial benefit. The statistical analyses of average selling prices indicate that refillable e-cigarettes are less expensive than traditional cigarettes. Obviously, every person deciding to exchange classic cigarettes for electronic devices should be aware of the initial expense. However, in terms of Polish costs, an initial financial burden is recovered after only a few days and vaping becomes more affordable in the long-term.

Presently, it is crucial to investigate the connection between both methods of nicotine intake and the probability of the occurrence of coronavirus disease (COVID-19), as well as its severity. It was proven that both smoking and vaping increase the chance of infection, although traditional smokers may be at a higher risk. As of now, there is an insufficient number of comprehensive studies which would uniquely determine if exposure to e-liquid aerosol (versus exposure to tobacco smoke) increases the gravity of the 
infectious process. The general awareness of the negative influence of e-cigarettes on the respiratory system seems to be sufficient to serve as an alert to individuals who vape and have a positive test result for SARS-CoV-2 infection.

Despite the advantages of e-cigarettes over classic cigarettes in many aspects, the e-cigarette phenomenon poses a whole new kind of threat to public health. As shown by large meta-analyses based on studies of young adults and adolescents aged 14-30, the odds ratio for the subsequent smoking of classic cigarettes between previous users of e-cigarettes and individuals who never used them is as high as 3.50 [80]. This indicates the high addictive potential of e-cigarettes among young people who, through these devices, begin their tobacco addiction at an early age and go on to use classic cigarettes.

It should be noted that more research is required in order to study the potential influence of e-cigarettes on human carcinogenesis as well as the potential association of vaping with the onset of COPD. Currently, no evidence exists regarding the safe use of e-cigarettes by pregnant women, therefore complete cessation of smoking and vaping is to be advised.

\section{Conclusions}

It should be acknowledged that despite the primary branding of e-cigarettes as a safer alternative to traditional cigarettes, this product is not devoid of negative impacts on the user's health. For this reason, they cannot be advised, especially to pregnant women. Despite present restrictions in their use, there is a range of indications for the replacement of classic cigarettes with electronic ones with well-documented benefits for the patient. The beneficiaries mainly include predominantly smoking individuals who are being treated for arterial hypertension or asthma, as well as smokers who want to minimize the harmful influence of passive smoking on their environment. The application of e-cigarettes is worth considering in patients who wish to permanently overcome their nicotine addiction. It may be especially recommended if previous trials of quitting smoking with a single NRT were ineffective. Due to the more frequently observed tobacco addiction among young people as a result of the use of e-cigarettes, this phenomenon should be perceived as a new threat to public health worldwide. In view of this threat, appropriate legal regulations limiting access to such devices and information campaigns on the harms of tobacco addiction should be implemented. Apart from the therapeutic implications mentioned above, electronic cigarettes may have other properties which should be a focus of study in the near future. In conclusion, a medical practitioner should track the progress of such research on an ongoing basis.

\section{Conflict of interests}

\section{None declared.}

\section{References:}

1. Pinkas J, Kaleta D, Zgliczyński WS, et al. The prevalence of tobacco and e-cigarette use in Poland: a 2019 nationwide cross-sectional survey. Int J Environ Res Public Health. 2019; 16(23), doi: 10.3390/ijerph16234820, indexed in Pubmed: 31801221.

2. Laverty AA, Filippidis FT, Vardavas CI. Patterns, trends and determinants of e-cigarette use in 28 European Union Member States 2014-2017. Prev Med. 2018; 116: 13-18, doi: 10.1016/j. ypmed.2018.08.028, indexed in Pubmed: 30144487.

3. Główny Inspektorat Sanitarny, Portal Gov.pl. Postawy Polaków wobec palenia tytoniu - Raport 2019 r. Główny Inspektorat Sanitarny. Available online: www.gov.pl/web/gis/postawy-polakow-wobec-palenia-tytoniu--raport-2017. [Last accessed at: 10.02.2021].

4. Yong HH, Borland R, Cummings KM, et al. Reasons for regular vaping and for its discontinuation among smokers and recent ex-smokers: findings from the 2016 ITC Four Country Smoking and Vaping Survey. Addiction. 2019; 114 Suppl 1: 35-48, doi: 10.1111/add.14593, indexed in Pubmed: 30821861.

5. Smith DM, Gawron M, Balwicki L, et al. Exclusive versus dual use of tobacco and electronic cigarettes among adolescents in Poland, 2010-2016. Addict Behav. 2019; 90: 341-348, doi: 10.1016/j.addbeh.2018.11.035, indexed in Pubmed: 30508744.

6. Słownik języka polskiego PWN. E-papieros — definicja, synonimy, przykłady użycia. Available online: https://sjp.pwn.pl/ slowniki/e-papieros.html. [Last accessed at: 10.02.2021].

7. Polish Journal of Laws from 1996, No. 10, item 55.

8. Shields PG, Berman M, Brasky TM, et al. A review of pulmonary toxicity of electronic cigarettes in the context of smoking: a focus on inflammation. Cancer Epidemiol Biomarkers Prev. 2017; 26(8): 1175-1191, doi: 10.1158/1055-9965.EPI-17-0358, indexed in Pubmed: 28642230.

9. Crotty Alexander LE, Shin S, Hwang JH. Inflammatory diseases of the lung induced by conventional cigarette smoke: a review. Chest. 2015; 148(5): 1307-1322, doi: 10.1378/chest.15-0409, indexed in Pubmed: 26135024.

10. Coussens LM, Werb Z. Inflammation and cancer. Nature. 2002; 420(6917): 860-867, doi: 10.1038/nature01322, indexed in Pubmed: 12490959.

11. De Smet EG, Mestdagh P, Vandesompele Jo, et al. Non-coding RNAs in the pathogenesis of COPD. Thorax. 2015; 70(8): 782791, doi: 10.1136/thoraxjnl-2014-206560, indexed in Pubmed: 25995155.

12. Jayes L, Haslam P, Gratziou C, et al. SmokeHaz. Chest. 2016; 150(1): 164-179, doi: 10.1016/j.chest.2016.03.060.

13. Burke H, Leonardi-Bee Jo, Hashim A, et al. Prenatal and passive smoke exposure and incidence of asthma and wheeze: systematic review and meta-analysis. Pediatrics. 2012; 129(4): 735-744, doi: 10.1542/peds.2011-2196, indexed in Pubmed: 22430451.

14. Merianos AL, Dixon CA, Mahabee-Gittens EM. Secondhand smoke exposure, illness severity, and resource utilization in pediatric emergency department patients with respiratory illnesses. J Asthma. 2017; 54(8): 798-806, doi: 10.1080/02770903.2016.1265127, indexed in Pubmed: 27929695.

15. den Dekker HT, Voort AMv, de Jongste JC, et al. Tobacco smoke exposure, airway resistance, and asthma in school-age children: the generation R study. Chest. 2015; 148(3): 607-617, doi: 10.1378/chest.14-1520, indexed in Pubmed: 25741773. 
16. Kaisar MA, Prasad S, Liles T, et al. A decade of e-cigarettes: Limited research \& unresolved safety concerns. Toxicology. 2016; 365: 67-75, doi: 10.1016/j.tox.2016.07.020, indexed in Pubmed: 27477296.

17. Vardavas C, Anagnostopoulos N, Kougias M, et al. Short-term pulmonary effects of using an electronic cigarette. Chest. 2012; 141(6): 1400-1406, doi: 10.1378/chest.11-2443.

18. Allen J, Flanigan S, LeBlanc M, et al. Flavoring chemicals in e-cigarettes: diacetyl, 2,3-pentanedione, and acetoin in a sample of 51 products, including fruit-, candy-, and cocktail-flavored e-cigarettes. Environmental Health Perspectives. 2016; 124(6): 733-739, doi: 10.1289/ehp.1510185.

19. Shivalingappa PC, Hole R, Westphal CV, et al. Airway exposure to e-cigarette vapors impairs autophagy and induces aggresome formation. Antioxid Redox Signal. 2016; 24(4): 186-204, doi: 10.1089/ars.2015.6367, indexed in Pubmed: 26377848.

20. Osei AD, Mirbolouk M, Orimoloye OA, et al. The association between e-cigarette use and asthma among never combustible cigarette smokers: behavioral risk factor surveillance system (BRFSS) 2016 \& 2017. BMC Pulm Med. 2019; 19(1): 180, doi: 10.1186/s12890-019-0950-3, indexed in Pubmed: 31619218.

21. Polosa R, Morjaria JB, Caponnetto P, et al. Persisting long term benefits of smoking abstinence and reduction in asthmatic smokers who have switched to electronic cigarettes. Discov Med. 2016; 21(114): 99-108, indexed in Pubmed: 27011045.

22. Mishra S. Are e-cigarettes beneficial for public health: Hume's guillotine. The debate continues? Indian Heart J. 2017; 69(6): 810-813, doi: 10.1016/j.ihj.2017.11.007, indexed in Pubmed: 29174270.

23. Layden JE, Ghinai I, Pray I, et al. Pulmonary illness related to e-cigarette use in illinois and wisconsin - final report. N Engl J Med. 2020; 382(10): 903-916, doi: 10.1056/NEJMoa1911614, indexed in Pubmed: 31491072.

24. Henry TS, Kanne JP, Kligerman SJ. Imaging of vaping-associated lung disease. N Engl J Med. 2019; 381(15): 1486-1487, doi: 10.1056/NEJMc1911995, indexed in Pubmed: 31491070.

25. Blount BC, Karwowski MP, Shields PG, et al. Vitamin E acetate in bronchoalveolar-lavage fluid associated with EVALI. N Engl J Med. 2020; 382(8): 697-705, doi: 10.1056/NEJMoa1916433, indexed in Pubmed: 31860793.

26. Health CO on S and. Smoking and Tobacco Use; Electronic Cigarettes. Centers for Disease Control and Prevention. 2020. Available online: www.cdc.gov/tobacco/basic_information/e-cigarettes/severe-lung-disease.html. [Last accessed at 10.02.2020].

27. Sobczak A. Zmierzch elektronicznych papierosów? Available online: www.mp.pl/social/article/224877. [Last accessed at: 10.02.2020].

28. National Center for Chronic Disease Prevention and Health Promotion (US) Office on Smoking and Health. The Health Consequences of Smoking-50 Years of Progress: A Report of the Surgeon General. Atlanta (GA): Centers for Disease Control and Prevention (US); 2014. Available online: www.ncbi.nlm. nih.gov/books/NBK179276/. [Last accessed at: 14.02.2021]. .

29. Laustiola KE, Lassila R, Nurmi AK. Enhanced activation of the renin-angiotensin-aldosterone system in chronic cigarette smokers: a study of monozygotic twin pairs discordant for smoking. Clin Pharmacol Ther. 1988; 44(4): 426-430, doi: 10.1038/clpt.1988.175, indexed in Pubmed: 3048842.

30. Nikotyna - Medycyna Praktyczna: opis, ceny, refundacja. Available online: www.mp.pl/pacjent/leki/subst.html?id=604. [Last accessed at: 10.02.2021].

31. Meurrens K, Ruf S, Ross G, et al. Smoking accelerates the progression of hypertension-induced myocardial hypertrophy to heart failure in spontaneously hypertensive rats. Cardiovasc Res. 2007; 76(2): 311-322, doi: 10.1016/j.cardiores.2007.06.033, indexed in Pubmed: 17658497.

32. Benowitz NL. Cigarette smoking and cardiovascular disease: pathophysiology and implications for treatment. Prog Cardiovasc Dis. 2003; 46(1): 91-111, doi: 10.1016/s00330620(03)00087-2, indexed in Pubmed: 12920702.

33. Kianoush S, Yakoob MY, Al-Rifai M, et al. Associations of cigarette smoking with subclinical inflammation and atherosclerosis: elsa-brasil (the brazilian longitudinal study of adult health). J Am Heart Assoc. 2017; 6(6), doi: 10.1161/ JAHA.116.005088, indexed in Pubmed: 28647689.
34. Pappas RS, Gray N, Gonzalez-Jimenez N, et al. Toxic metal concentrations in mainstream smoke from cigarettes available in the USA. J Anal Toxicol. 2014; 38(4): 204-211, doi: 10.1093/ jat/bku013, indexed in Pubmed: 24535337.

35. Bernhard D, Csordas A, Henderson B, et al. Cigarette smoke metal-catalyzed protein oxidation leads to vascular endothelial cell contraction by depolymerization of microtubules. FASEB J. 2005; 19(9): 1096-1107, doi: 10.1096/fj.04-3192com, indexed in Pubmed: 15985533.

36. Abu-Hayyeh S, Sian M, Jones KG, et al. Cadmium accumulation in aortas of smokers. Arterioscler Thromb Vasc Biol. 2001; 21(5): 863-867, doi: 10.1161/01.atv.21.5.863, indexed in Pubmed: 11348888.

37. Farsalinos KE, Voudris V, Poulas K. Are metals emitted from electronic cigarettes a reason for health concern? A risk-assessment analysis of currently available literature. Int J Environ Res Public Health. 2015; 12(5): 5215-5232, doi: 10.3390/ ijerph120505215, indexed in Pubmed: 25988311.

38. Goniewicz ML, Gupta R, Lee YH, et al. Nicotine levels in electronic cigarette refill solutions: A comparative analysis of products from the U.S., Korea, and Poland. Int J Drug Policy. 2015; 26(6): 583-588, doi: 10.1016/j.drugpo.2015.01.020, indexed in Pubmed: 25724267.

39. Yan XS, D'Ruiz C. Effects of using electronic cigarettes on nicotine delivery and cardiovascular function in comparison with regular cigarettes. Regul Toxicol Pharmacol. 2015; 71(1): 24-34, doi: 10.1016/j.yrtph.2014.11.004, indexed in Pubmed: 25460033.

40. Polosa R, Morjaria JB, Caponnetto P, et al. Blood pressure control in smokers with arterial hypertension who switched to electronic cigarettes. Int J Environ Res Public Health. 2016; 13(11), doi: 10.3390/ijerph13111123, indexed in Pubmed: 27845734.

41. Polosa R, Cibella F, Caponnetto P, et al. Health impact of e-cigarettes: a prospective 3.5-year study of regular daily users who have never smoked. Sci Rep. 2017; 7(1): 13825, doi: 10.1038/ s41598-017-14043-2, indexed in Pubmed: 29150612.

42. List of Classifications - IARC Monographs on the Identification of Carcinogenic Hazards to Humans. Available online: https:/ monographs.iarc.who.int/list-of-classifications. [Last accessed at 10.02.2021]

43. Prevention (US) C for DC and, Promotion (US) NC for CDP and $\mathrm{H}$, Health (US) O on S and. Figure 5.1, Link between cigarette smoking and cancer through carcinogens in tobacco smoke. Centers for Disease Control and Prevention (US); 2010. Available online: www.ncbi.nlm.nih.gov/books/NBK53010/figure/ ch5.f1/. [Last accessed at 1.02.2021].

44. National Academies of Sciences, Engineering, and Medicine, Health and Medicine Division, Board on Population Health and Public Health Practice, Committee on the Review of the Health Effects of Electronic Nicotine Delivery Systems. Public Health Consequences of E-Cigarettes. Eaton DL, Kwan LY, Stratton K, editors. Washington (DC): National Academies Press (US); 2018. Available online: www.ncbi.nlm.nih.gov/ books/NBK507171/. [Last accessed at: 10.02.2021].

45. Mravec B, Tibensky M, Horvathova L, et al. E-Cigarettes and cancer risk. Cancer Prev Res (Phila). 2020; 13(2): 137-144, doi: 10.1158/1940-6207.CAPR-19-0346, indexed in Pubmed: 31619443.

46. Pham K, Huynh Do, Le Le, et al. E-cigarette promotes breast carcinoma progression and lung metastasis: Macrophage-tumor cells crosstalk and the role of CCL5 and VCAM-1. Cancer Lett. 2020; 491: 132-145, doi: 10.1016/j.canlet.2020.08.010, indexed in Pubmed: 32829009.

47. Lee HW, Park SH, Weng MW, et al. E-cigarette smoke damages DNA and reduces repair activity in mouse lung, heart, and bladder as well as in human lung and bladder cells. Proc Natl Acad Sci U S A. 2018; 115(7): E1560-E1569, doi: 10.1073/ pnas.1718185115, indexed in Pubmed: 29378943.

48. Visser WF, Klerx WN, Cremers HW, et al. The health risks of electronic cigarette use to bystanders. Int J Environ Res Public Health. 2019; 16(9), doi: 10.3390/ijerph16091525, indexed in Pubmed: 31052162 .

49. Czogala J, Goniewicz ML, Fidelus B, et al. Secondhand exposure to vapors from electronic cigarettes. Nicotine Tob Res. 2014; 16(6): 655-662, doi: 10.1093/ntr/ntt203, indexed in Pubmed: 24336346. 
50. Campus G, Cagetti MG, Senna A, et al. Does smoking increase risk for caries? A cross-sectional study in an Italian military academy. Caries Res. 2011; 45(1): 40-46, doi: 10.1159/000322852, indexed in Pubmed: 21228593.

51. Coretti L, Cuomo M, Florio E, et al. Subgingival dysbiosis in smoker and nonsmoker patients with chronic periodontitis. Mol Med Rep. 2017; 15(4): 2007-2014, doi: 10.3892/ mmr.2017.6269, indexed in Pubmed: 28260061.

52. Sm M, Si A. Tobacco-associated lesions of the oral cavity: Part I. Nonmalignant lesions. Vol. 66, Journal (Canadian Dental Association). J Can Dent Assoc; 2000. Available onhttps:// pubmed-1ncbi-1nlm-1nih-1gov-100001anf0279.han3.wum. edu.pl/10833868/. [Last accessed at: 10.02.2021].

53. Irusa KF, Vence B, Donovan T. Potential oral health effects of e-cigarettes and vaping: A review and case reports. J Esthet Restor Dent. 2020; 32(3): 260-264, doi: 10.1111/jerd.12583, indexed in Pubmed: 32243711.

54. Vora MV, Chaffee BW. Tobacco-use patterns and self-reported oral health outcomes: A cross-sectional assessment of the Population Assessment of Tobacco and Health study, 2013-2014. J Am Dent Assoc. 2019; 150(5): 332-344.e2, doi: 10.1016/j. adaj.2018.12.004, indexed in Pubmed: 30922519.

55. Javed F, Abduljabbar T, Vohra F, et al. Comparison of periodontal parameters and self-perceived oral symptoms among cigarette smokers, individuals vaping electronic cigarettes, and never-smokers. J Periodontol. 2017; 88(10): 1059-1065, doi: 10.1902/jop.2017.170197, indexed in Pubmed: 28644108.

56. Tatullo M, Gentile S, Paduano F, et al. Crosstalk between oral and general health status in e-smokers. Medicine (Baltimore). 2016; 95(49): e5589, doi: 10.1097/MD.0000000000005589, indexed in Pubmed: 27930577.

57. Polosa R, Morjaria JB, Caponnetto P, et al. Effectiveness and tolerability of electronic cigarette in real-life: a 24-month prospective observational study. Intern Emerg Med. 2014; 9(5): 537-546, doi: 10.1007/s11739-013-0977-z, indexed in Pubmed: 23873169.

58. Rouabhia M, Semlali A. Electronic cigarette vapor increases Streptococcus mutans growth, adhesion, biofilm formation, and expression of the biofilm-associated genes. Oral Dis. 2021; 27(3): 639-647, doi: 10.1111/odi.13564, indexed in Pubmed: 32683796.

59. Smoking and infertility: a committee opinion. Fertil Steril. 2018 Sep 1.; 110(4): 611-618.

60. Wetendorf M, Randall LT, Lemma MT, et al. E-Cigarette exposure delays implantation and causes reduced weight gain in female offspring exposed . J Endocr Soc. 2019; 3(10): 1907-1916, doi: 10.1210/js.2019-00216, indexed in Pubmed: 31598571.

61. El Golli N, Rahali D, Jrad-Lamine A, et al. Impact of electronic-cigarette refill liquid on rat testis. Toxicol Mech Methods. 2016; 26(6): 427-434, doi: 10.3109/15376516.2016.1163448, indexed in Pubmed: 27098213.

62. McCubbin A, Fallin-Bennett A, Barnett J, et al. Perceptions and use of electronic cigarettes in pregnancy. Health Educ Res. 2017; 32(1): 22-32, doi: 10.1093/her/cyw059, indexed in Pubmed: 28158490.

63. Chiang SC, Abroms LC, Cleary SD, et al. E-cigarettes and smoking cessation: a prospective study of a national sample of pregnant smokers. BMC Public Health. 2019; 19(1): 964, doi: 10.1186/s12889-019-7299-7, indexed in Pubmed: 31319846.

64. Wisborg K, Henriksen TB, Jespersen LB, et al. Nicotine patches for pregnant smokers: a randomized controlled study. Obstet Gynecol. 2000; 96(6): 967-971, doi: 10.1016/s00297844(00)01071-1, indexed in Pubmed: 11084187.

65. Coleman T, Cooper S, Thornton JG, et al. A randomized trial of nicotine-replacement therapy patches in pregnancy. N Engl J Med. 2012; 366(9): 808-818, doi: 10.1056/NEJMoa1109582, indexed in Pubmed: 22375972.

66. Orzabal MR, Lunde-Young ER, Ramirez JI, et al. Chronic exposure to e-cig aerosols during early development causes vas- cular dysfunction and offspring growth deficits. Transl Res. 2019; 207: 70-82, doi: 10.1016/j.trsl.2019.01.001, indexed in Pubmed: 30653941.

67. Liber AC, Drope JM, Stoklosa M. Combustible cigarettes cost less to use than e-cigarettes: global evidence and tax policy implications. Tob Control. 2017; 26(2): 158-163, doi: 10.1136/tobaccocontrol-2015-052874, indexed in Pubmed: 27022059.

68. Barrington-Trimis JL, Berhane K, Unger JB, et al. The e-cigarette social environment, e-cigarette use, and susceptibility to cigarette smoking. J Adolesc Health. 2016; 59(1): 75-80, doi: 10.1016/j.jadohealth.2016.03.019, indexed in Pubmed: 27161417.

69. McCabe SE, Veliz P, McCabe VV, et al. Smoking behaviors and intentions among current e-cigarette users, cigarette smokers, and dual users: A national survey of U.S. high school seniors. Prev Med. 2017; 99: 228-235, doi: 10.1016/j. ypmed.2017.02.025, indexed in Pubmed: 28257785.

70. Selya AS, Dierker L, Rose JS, et al. The role of nicotine dependence in e-cigarettes' potential for smoking reduction. Nicotine Tob Res. 2018; 20(10): 1272-1277, doi: 10.1093/ntr/ntx160, indexed in Pubmed: 29065204.

71. Morean ME, Krishnan-Sarin S, O’Malley SS, et al. Comparing cigarette and e-cigarette dependence and predicting frequency of smoking and e-cigarette use in dual-users of cigarettes and e-cigarettes. Addict Behav. 2018; 87: 92-96, doi: 10.1016/j. addbeh.2018.06.027, indexed in Pubmed: 29975879.

72. Liu G, Wasserman E, Kong L, et al. A comparison of nicotine dependence among exclusive E-cigarette and cigarette users in the PATH study. Prev Med. 2017; 104: 86-91, doi: 10.1016/j. ypmed.2017.04.001, indexed in Pubmed: 28389330.

73. Hajek P, Phillips-Waller A, Przulj D, et al. A randomized trial of e-cigarettes versus nicotine-replacement therapy. N Engl J Med. 2019; 380(7): 629-637, doi: 10.1056/NEJMoa1808779, indexed in Pubmed: 30699054.

74. Walker N, Parag V, Verbiest M, et al. Nicotine patches used in combination with e-cigarettes (with and without nicotine) for smoking cessation: a pragmatic, randomised trial. Lancet Respir Med. 2020; 8(1): 54-64, doi: 10.1016/S22132600(19)30269-3, indexed in Pubmed: 31515173.

75. Dawkins L, Munafò M, Christoforou G, et al. The effects of e-cigarette visual appearance on craving and withdrawal symptoms in abstinent smokers. Psychol Addict Behav. 2016 30(1): 101-105, doi: 10.1037/adb0000112, indexed in Pubmed: 26415054.

76. Lee A, Chakladar J, Li W, et al. Tobacco, but not nicotine and flavor-less electronic cigarettes, induces ACE2 and immune dysregulation. Int J Mol Sci. . 2020; 21(15): 5513, doi: 10.1101/2020.07.13.198630.

77. Reddy RK, Charles WN, Sklavounos A, et al. The effect of smoking on COVID-19 severity: A systematic review and meta-analysis. J Med Virol. 2021; 93(2): 1045-1056, doi: 10.1002/ jmv.26389, indexed in Pubmed: 32749705.

78. Gaiha SM, Cheng J, Halpern-Felsher B. Association between youth smoking, electronic cigarette use, and COVID-19. J Adolesc Health. 2020; 67(4): 519-523, doi: 10.1016/j. jadohealth.2020.07.002, indexed in Pubmed: 32798097.

79. Münzel T, Hahad O, Kuntic M, et al. Effects of tobacco cigarettes, e-cigarettes, and waterpipe smoking on endothelial function and clinical outcomes. Eur Heart J. 2020; 41(41): 4057-4070, doi: 10.1093/eurheartj/ehaa460, indexed in Pubmed: 32585699.

80. Soneji S, Barrington-Trimis JL, Wills TA, et al. Association between initial use of e-Cigarettes and subsequent cigarette smoking among adolescents and young adults: a systematic review and meta-analysis. JAMA Pediatr. 2017; 171(8): 788-797, doi: 10.1001/ jamapediatrics.2017.1488, indexed in Pubmed: 28654986. 